Space invaders: race, gender and bodies out of place

Nirmal Puwar, Berg, 0xford, 2004, 224p, ISBN 1-8597-3659-9, £15.99 (Pbk);

ISBN 1-8597-3654-8, £47.00 (Hbk)

I am standing in the administrators' office in the philosophy department. The department has one female and two male administrative assistants. Even though one of the male assistants is looking directly and attentively at a student making an enquiry, this student wants to engage my attention, though I am clearly otherwise occupied. This student expects and wants me to be the administrator. I am a female professor in an administrative space, standing alongside a male administrator in an administrative space. Yet the student sees only one of these two bodies as being the 'appropriate' one to help, to 'serve', and to attend to his needs. Entering a lift, a 'black' parliamentarian is mistaken for cleaning or catering staff by one of his ('white') colleagues: 'only Members [of Parliament] can go in the lift' his helpful colleague volunteers (p. 42). What underlies these cases of mistaken identity? What do these occurrences tell us about bodies and spaces and belonging, and about the notion of 'bodies out of place'?

This beautifully written and evocative book succeeds in articulating a clear and convincing account of what grounds these common and - at least for those being 'mis-identified' - psychically exhausting encounters. Nirmal Puwar masterfully brings together a range of recent feminist, political and 'race'-studies theories and couples these with fascinating and original empirical research. The 'neutrality' of the human body has been thoroughly criticized by feminists and others. The human body, it has been shown, does not exist except as a questionable theoretical entity. Bodies are constructed through a variety of social and political practices as sexed, 'raced', 'disabled', 'abnormal', and so on; and these practices have a history that impacts upon everyday habits, behaviour and actions. None of this is news, of course, to those who are on the receiving end of the assumptions and habituated reflexes of 'elite' identities and their comfortable occupation of those spaces to which they feel entitled. However, one of the extraordinary achievements of this book is the manner in which it repositions the gaze of the social analyst to make visible 'whiteness' and masculinity and the 'fit' of some identities with certain privileged spaces. In this respect, Space Invaders deserves a place alongside other path-breaking works such as Carole Pateman's The Sexual Contract and Charles Mills's The Racial Contract. Puwar builds upon this very important research and combines it with recent work on the politics of space, place and belonging. Her thesis, in short, is that space is no less neutral than 'the body'. '[S]ocial spaces are not blank and open for any body to occupy' (p. 8). No less than the body, spaces are socially and politically constructed, and they have a history that will effect the meaning of that (particular) body occupying this (particular) space. Space Invaders offers 
many examples of the mismatch between certain bodies and certain spaces, or situations where bodies appear 'out of place'. What effect do the presence of women's and/or 'black' bodies have in the halls of Westminster? Why does the placement of a statue of Nelson Mandela in that most iconic of British spaces, Trafalgar Square, threaten to unsettle 'British' identity and history? Puwar's response is that the presence of women and non-white bodies in positions that have traditionally been reserved for 'white', masculine, bodies exposes the sedimented relationship between gendered and racialized bodies and spaces. The 'unmarked' white male body and the naturalization of its exclusive right to be master of political spaces becomes a marked body and its privilege is progressively de-naturalized in the pages of this book.

Taking up Mills' notion of the somatic norm Puwar shows how the specificity of raced and sexed embodiment constrains one's ability to occupy putatively 'neutral' space. Making excellent use of interview materials and astute social science observation, the body emerges as a thoroughly politicized entity that may be enabled or constrained through the social practices and public spaces that help constitute its particularity. By analysing contemporary examples of 'bodies out of place', Puwar shows 'the ways in which bodies have been coupled with and decoupled from specific occupational [and other] spaces' (p. 78). Puwar's research brings fascinating quantitative and qualitative applied research to 'high' theory and the results are deeply edifying. The particularity of the somatic norm, simply assumed in much social and political theory, is analysed in a way that emphasizes the construction, and so deconstruction, of privilege. Space Invaders considers a range of cultural practices and places and draws out their aesthetic, ethical and political significance. The elegance of the writing is especially noticeable in those passages where Puwar evokes for us a lively scene: place includes sounds, smells and tactility as well as actions and practices, and together these form a general habitus. Although this book deals with complex theoretical issues, and treats some sobering problems in contemporary multicultural societies, it always remains accessibly written, good humoured and surprisingly uplifting. Space Invaders should be compulsory reading for any body that occupies any space.

doi: $10.1057 /$ palgrave.fr. 9400370

Moira Gatens

\section{Reclaiming female agency: feminist art history after postmodernism}

Norma Broude and Mary D. Garrard (editors); University of California Press, Berkeley, Los Angeles, London, 2005, 478 p, ISBN 0-520-24251-3 £40.95 (Cloth); 0-520-24252-1 £26.95 (Pbk)

This is a big book in every sense, the third anthology of essays that Norma Broude and Mary D. Garrard have co-edited over the last two decades, encompassing 